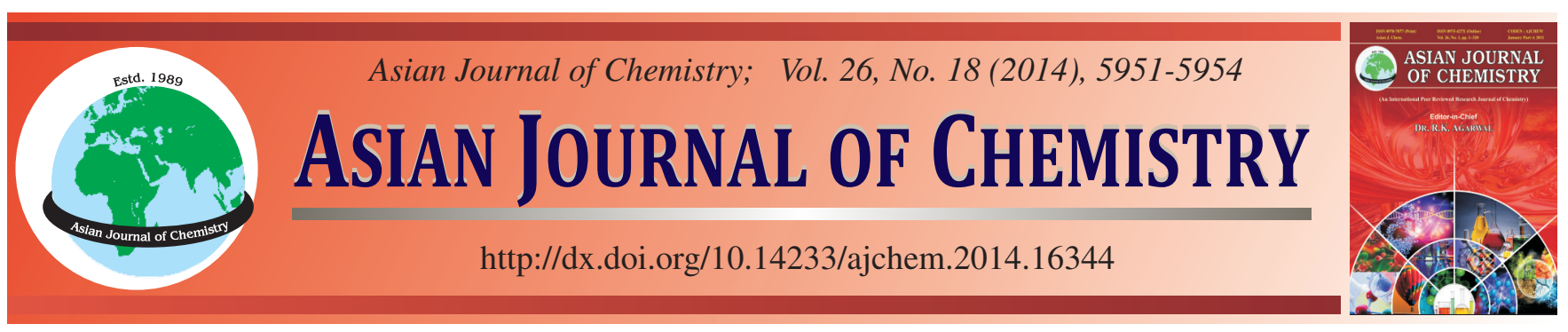

\title{
Application of Graphene/Tetraphenylboron-Dopamine Modified Graphite Electrode for Selective Determination of Dopamine
}

\author{
Jing Zhang ${ }^{\dagger}$, Chang Liu ${ }^{\dagger}$, Yifeng E, Jingli Yue, Lianshan Chen and Donghui Li*
}

Liaoning Medical University, Jinzhou 121001, P.R. China

*Corresponding author: E-mail: lidonghuilx@ sina.com

$\nmid$ These two authors made equal contribution to this work

A novel electrochemical sensor based on graphene and tetraphenylboron-dopamine electroactive material was developed for determination of dopamine which is correlative to some neurogenic disease. Graphene was synthesized by one-step liquid-phase exfoliation of graphite and the tetraphenylboron-dopamine was prepared by precipitation reaction on formation of ion association complex. The resultant electrode showed better performance in selectivity, sensitivity and narrow potential window comparing with bare graphite electrode and graphite electrode modified by tetraphenylboron-dopamine. In the presence of 1000-fold concentration interference of ascorbic acid and uric acid, the linear range for dopamine was successfully determined from $1 \times 10^{-4}$ to $1 \times 10^{-10} \mathrm{~mol} / \mathrm{L}$ with a correlation coefficient of 0.9969 . The detection limit was estimated to be $7.39 \times 10^{-11} \mathrm{~mol} / \mathrm{L}$ in 3 of signal to noise ratio $(\mathrm{S} / \mathrm{N}=3)$. According with successive measurements in 10 times, the relative standard deviation of all results for graphene/tetraphenylboron-dopamine /graphite electrode still kept in $1.83 \%$. Moreover, the graphene/tetraphenylboron-dopamine/graphite electrode could be stored for 30 days in $4^{\circ} \mathrm{C}$ without sharply decrease of its electroactivity. All results clearly prove that this modified electrode is sensitive way for selective determination of dopamine.

Keywords: Graphene, Tetraphenylborate, Dopamine, Modified electrode.

\section{INTRODUCTION}

Dopamine, as one of the important neurotransmitters, plays a significant role in the function of human metabolism, cardiovascular, central nervous, renal and hormonal systems ${ }^{1}$. Deficiency of dopamine may cause some neurological diseases such as Schizophrenia, Huntington's disease and Parkinson's disease $^{2}$. There are some methods for the requirements of dopamine determination, which include spectrophotometry ${ }^{3,4}$, high performance liquid chromatography (HPLC) ${ }^{5}$, flow injection chemiluminescence ${ }^{6}$, spectrofluorimetry and capillary electrophoresis mass spectrometry ${ }^{7}$. Even though these methods exhibit high sensitivity, but require expensive instruments, long analysis times, troublesome and time-consuming pretreatment. Hence, a rapid, low-cost, sensitive and selective method is strongly required to satisfy real application for clinical diagnosis and pathological analysis.

Electrochemical measurements as a traditional analytical technique have been widely used in the determination of biological samples because of its intrinsic advantages such as portability, low-energy consumption and low-cost ${ }^{8}$. Therefore, the determination of dopamine based on its electrochemical activity in field of electrochemistry has attracted a dramatical interest ${ }^{9-11}$. However, the coexistence of ascorbic acid and uric acid with 100-1000 times of concentrations than that of dopamine interferes dopamine determination seriously, especially for overlapping oxidized potential at traditional bare electrodes. In order to overcome the difficulties of traditional dopamine determination, new techniques are needed to be developed.

In order to enhance the sensitivity and selectivity of the electrochemical sensors, a variety of materials have been employed to modify electrode. Graphene, a flat monolayer of carbon atoms tightly arranged in a two-dimensional (2D) honeycomb lattice, has been realized in 2004. It is the newest member of the carbon family that can be wrapped up into OD fullerenes, rolled into 1D nanotubes or stacked into 3D graphite. Advantages of electronic conductivity, high specific surface area and chemical stability provide a suitable microenvironment for biomolecules immobilization and facilitate electron transfer between immobilized biomolecules and electrode ${ }^{12-19}$. These promising properties together make graphene-based materials ideal candidates for the application in many areas including electrochemical sensing and biosensing ${ }^{20-22}$.

Tetraphenylborate has been used in the formation of many sensors as a well-known ion exchanger ${ }^{23,24}$. Because of the interactions between the particles, tetraphenylborate ions with negative charges are able to exclude same negative ions but attract positive ions from the membrane ${ }^{25}$. In the present 
research, dopamine was reacted with tetraphenylborate in the formation of a water insoluble ion association complex as an electrochemically active material used. The high lipophilicity of the complex suggests its suitable use in polyvinylchloride (PVC) matrix membrane sensors. To combine advantages of graphene and the electrochemical technique, a novel graphene/ tetraphenylboron-dopamine modified graphite electrode own the excellent ability to determine dopamine in a rapid, selective, sensitive and low-cost way.

\section{EXPERIMENTAL}

Dopamine hydrochloride was purchased from SigmaAldrich (Germany), (+)-sodium L-ascorbate and uric acid was obtained from Sigma-Aldrich (China). Graphite was obtained from Tianjin Chemical Reagent Factory (China). Tetraphenylboron sodium, tetrahydrofuran, N,N-dimethyl formamide and dibutyl phthalate were purchased from Sinopharm Chemical Reagent Co., Ltd (China). Polyvinylchloride powder was obtained from Sandong haihua Co., Ltd (China). All the reagents used in this study were of analytical grade. All electrochemical measurements were performed by a CHI650D workstation (Chen Hua, Shanghai). A graphene/tetraphenylboron-dopamine modified graphite electrode, a platinum wire and an $\mathrm{Ag} / \mathrm{AgCl}$ electrode were used to complete the three-electrode system.

Synthesis of graphene: The graphite with a concentration of $0.1 \mathrm{mg} / \mathrm{mL}$ was dispersed in $25 \mathrm{~mL} \mathrm{~N}, \mathrm{~N}$-dimethyl formamide solution by sonicating for $30 \mathrm{~min}$. Then the resultant dispersion was centrifuged for $90 \mathrm{~min}$ at $500 \mathrm{rpm}^{26}$.

Preparation of tetraphenylboron-dopamine electrochemically active material: $0.1 \mathrm{~mol} / \mathrm{L}$ Dopamine hydrochloride solution was added to $0.1 \mathrm{~mol} / \mathrm{L}$ tetraphenylboron sodium solution in the equal volume. Flocculent white precipitates quickly generated. Then the precipitates were filtered with the No. 3 sand core funnel and washed with distilled water. The clean precipitates were stored in a desiccator until constant weight obtained.

Preparation of graphene/tetraphenylboron-dopamine/ graphite electrode: A mixture containing $1.5 \mathrm{~mL}$ graphene suspension, $20 \mathrm{mg}$ tetraphenylboron-dopamine with $0.3 \mathrm{~mL}$ dibutyl phthalate, $100 \mathrm{mg}$ PVC and $3 \mathrm{~mL}$ tetrahydrofuran was prepared and shaken vigorously. Then the polished graphite electrode was dipped into the mixture mentioned above. A graphene/tetraphenylboron-dopamine/graphite electrode fabricated for a working electrode was gotten when the mixture coated on the graphite electrode tightly.

\section{RESULTS AND DISCUSSION}

The SEM images graphene (a), graphene/tetraphenylborondopamine complexes (b) and graphene/tetraphenylborondopamine/graphite electrode (c) are shown in Fig. 1. From Fig. 1a showed that graphene nanosheets are as thin as transparent paper. It means that these nanosheets were exfoliated successfully from graphite. Fig. 1b shows that graphene nanosheets were packed with tetraphenylboron-dopamine evenly. It can also be proven that graphene/tetraphenylborondopamine complexes are uniformly wrapped in the surface of graphite electrode (Fig. 1c).

Electrochemical response of dopamine at the graphene/ tetraphenylboron-dopamine/graphite electrode: For studying advantages of graphene/tetraphenylboron-dopamine/graphite electrode, the cyclic voltammograms (CVs) was used to determine the performance of the bare graphite electrode, tetraphenylboron-dopamine/graphite electrode and graphene/tetraphenylboron-dopamine/graphite electrode, respectively. As shown in Fig. 2, the oxidation peak current of dopamine on the surface of graphene/tetraphenylboron-dopamine/graphite electrode is $378.9 \mathrm{uA}$, which is the largest peak current because of the great conductivity. To compare with other tested electrodes, the smaller $\Delta \mathrm{E}_{\mathrm{p}}$ of graphene/tetraphenylboron-dopamine/ graphite electrode is $137 \mathrm{mV}$ means better reversibility.

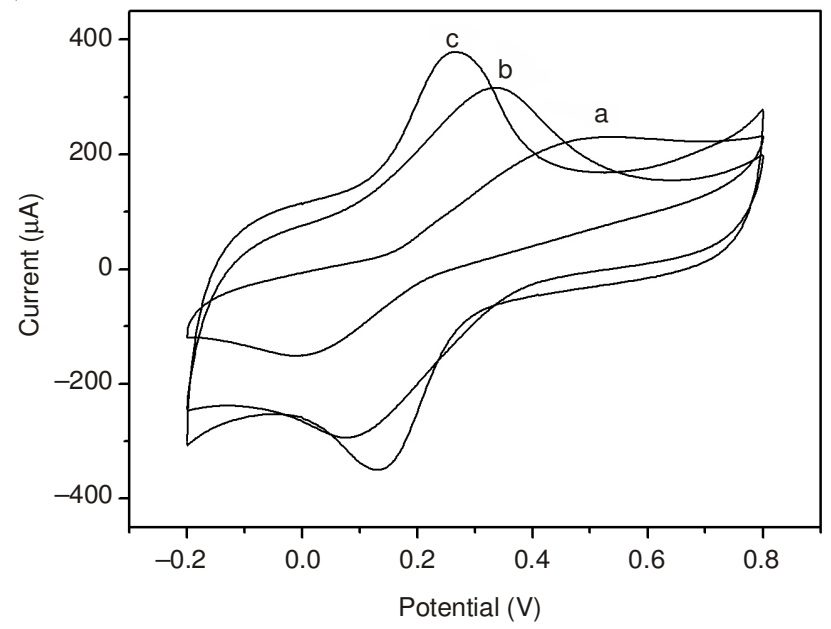

Fig. 2. Cyclic voltammograms of bare graphite electrode (a), tetraphenylboron-dopamine/graphite electrode (b), graphene/ tetraphenylboron-dopamine/graphite electrode (c) in $0.1 \mathrm{~mol} / \mathrm{L}$ phosphate buffer $(\mathrm{pH} 7)$ containing $1 \times 10^{-4} \mathrm{~mol} / \mathrm{L}$ dopamine. Scan rate: $100 \mathrm{mV} \mathrm{s}^{-1}$
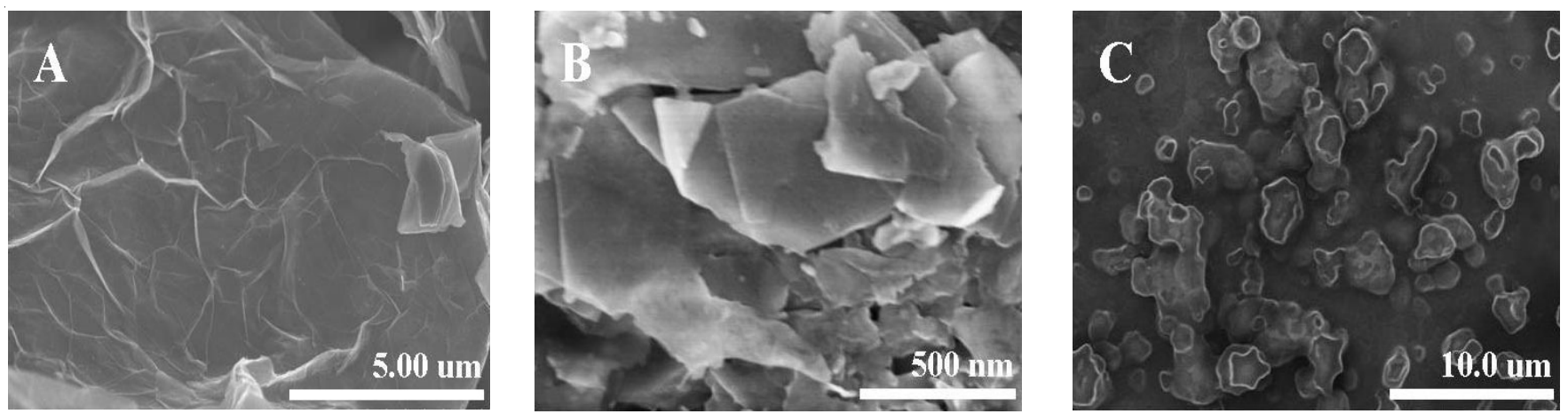

Fig. 1. Scanning electron microscope of images of graphene (a), Graphene/tetraphenylboron-dopamine complexes (b) and graphene/tetraphenylborondopamine/graphite electrode (c) 
Effect of pH: The effects of $\mathrm{pH}$ on the graphene/tetraphenylboron-dopamine/graphite electrode were investigated in the concentration of $1 \times 10^{-4} \mathrm{~mol} / \mathrm{L}$ dopamine solution. Fig. $3 \mathrm{a}$ shows the relationship between the anodic peak potential of dopamine and the $\mathrm{pH}$ value. It can be seen that the anodic peak potential decreases obviously with the increase of $\mathrm{pH}$. The linear regression equation is as follows: Epa $(\mathrm{mV})=$ $646.095-53.63 \mathrm{pH}$ and the correlation coefficient is -0.9975 . A slope of $-53.63 \mathrm{mV} / \mathrm{pH}$ indicates that the proportion of the electron and proton involved in the reactions is equal. The maximum current was obtained at $\mathrm{pH} 7$ and close to the physiological $\mathrm{pH}$ conditions (Fig. 3b). Therefore, $\mathrm{pH} 7$ was chosen for the subsequent experiments and provides the possibility of real samples' determination.
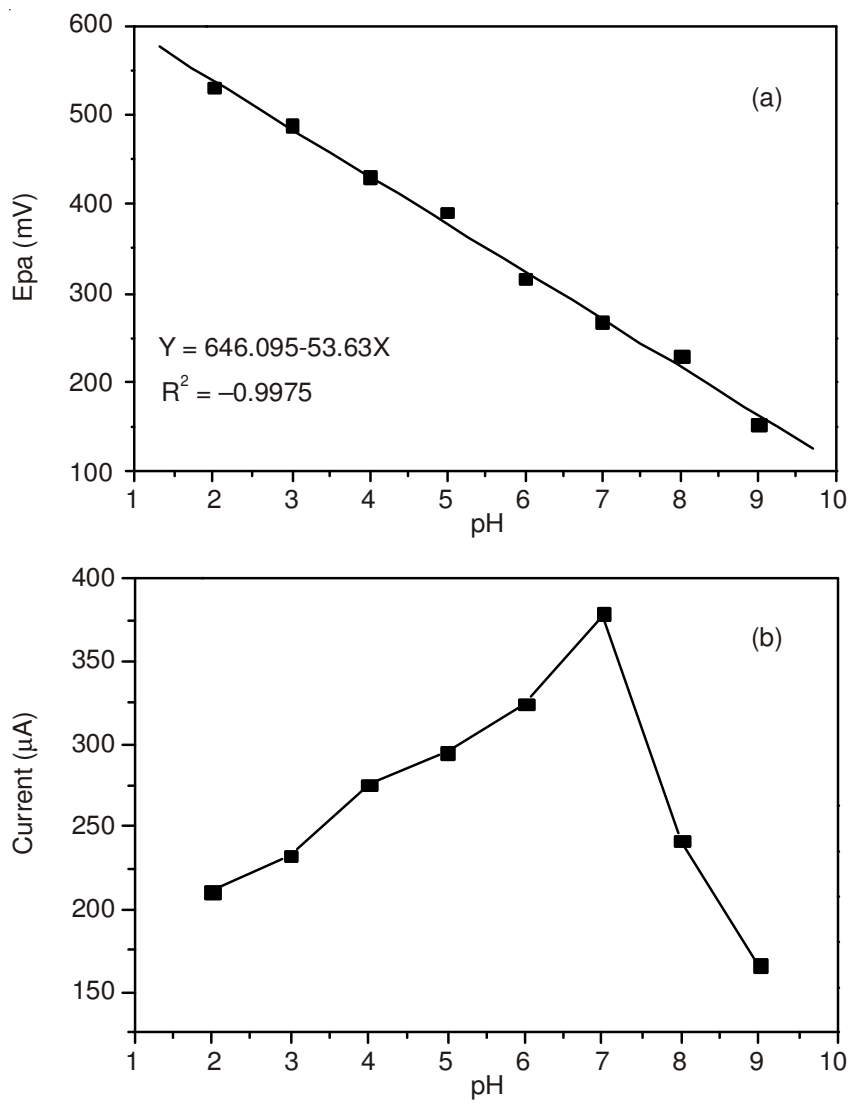

Fig. 3. Plots of variation of Epa (a) and Ipa (b) with $\mathrm{pH}$ change in the concentration of $1 \times 10^{-4} \mathrm{~mol} / \mathrm{L}$ dopamine solution at the surface of graphene/tetraphenylboron-dopamine/graphite electrode. Scan rate: $100 \mathrm{mV} \mathrm{s}^{-1}$
Effect of scan rate: Fig. 4a shows the cyclic-voltammogram curves of $1 \times 10^{-4} \mathrm{~mol} / \mathrm{L}$ dopamine at the surface of graphene/tetraphenylboron-dopamine/graphite electrode with different scan rates in the range of $20-200 \mathrm{mV} / \mathrm{s}$. The proportional increase of anodic peak current versus increase of scan rate is shown in Fig. 4b. The ideal correlation coefficient proves that the redox reaction of dopamine toward the graphene/ tetraphenylboron-dopamine/graphite electrode is a typically adsorption-controlled process. Fig. 4c shows a good linear relationship between the anodic peak current and the square root of the scan rate. It indicates that the reaction of electron transfer is a diffusion-controlled process. So our electrode process is controlled by both process of adsorption and diffusion simultaneously.

Selective determination of dopamine: The selectivity of graphene/tetraphenylboron-dopamine/graphite electrode for dopamine had been researched in the mixture containing conventional interference. Fig. 5a shows the cyclic-voltammogram curves of $1 \times 10^{-4} \mathrm{~mol} / \mathrm{L}$ dopamine, $0.1 \mathrm{~mol} / \mathrm{L}$ ascorbic acid and $0.1 \mathrm{~mol} / \mathrm{L}$ uric acid (a), $0.1 \mathrm{~mol} / \mathrm{L}$ ascorbic acid (b), $0.1 \mathrm{~mol} / \mathrm{L}$ uric acid (c) and blank phosphate buffer (d) at the modified electrode with a scan rate of $100 \mathrm{mV} / \mathrm{s}$. In 1000 times presence of ascorbic acid and uric acid than the dopamine, the oxidation peak current and $\Delta \mathrm{E}_{\mathrm{p}}$ of dopamine on the surface of graphene/tetraphenylboron-dopamine/graphite electrode are $379.6 \mathrm{uA}$ and $137.3 \mathrm{mV}$ which are extremely similar to only presence of dopamine. It means our graphene/tetraphenylborondopamine/graphite electrode provides its excellent selectivity for dopamine because dopamine is only positive charge comparing with ascorbic acid and uric acid when they are dissolved into water. According to a principle of ion-selective electrodes based on permselectivity, the tetraphenylborate ions of tetraphenylboron-dopamine with the negative charges just allow ions with positive charge such as dopamine passing through the membrane phase. Additionally, graphene was wrapped in tetraphenylboron-dopamine, the feasible electron transfer between graphene and phenyl structure of dopamine promotes the selectivity and sensitivity of modified electrode since special $\pi-\pi$ interaction unlike ascorbic acid and uric acid. Fig. $5 b$ shows calibrating plots of the anodic peak current versus logarithm of the dopamine concentrations. The linear regression equation follows as: $\mathrm{I}(\mu \mathrm{A})=572.559+49.605 \log \mathrm{C}(\mathrm{mol} / \mathrm{L})$ and the correlation coefficient is 0.9969 . Then the detection limit is gotten as $7.39 \times 10^{-11} \mathrm{~mol} / \mathrm{L}$ with noise-signal ratio in 3 .
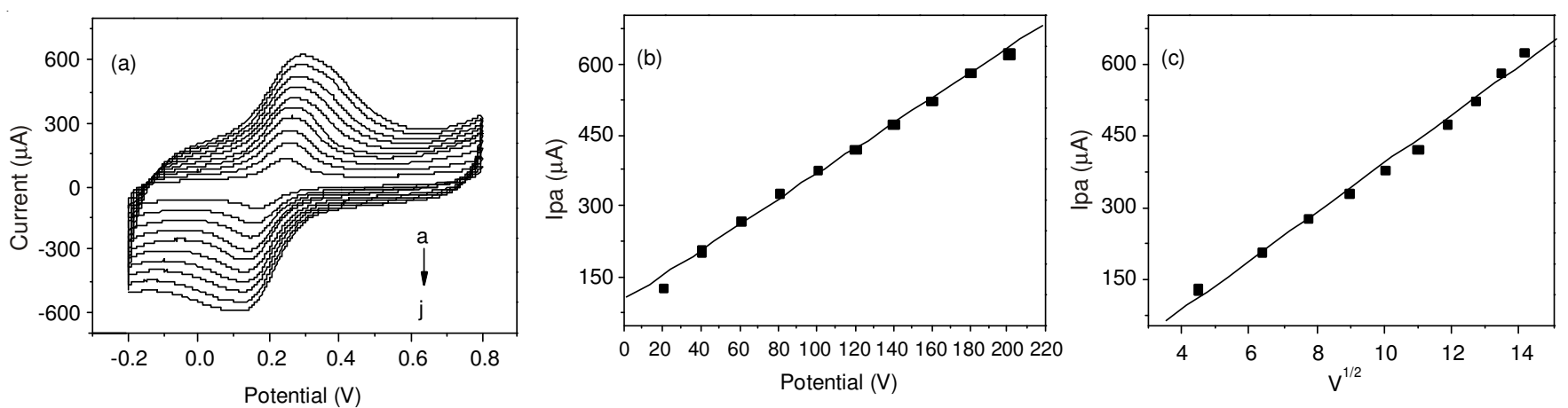

Fig. 4. Cyclic voltammograms of graphene/tetraphenylboron-dopamine/graphite electrode in $0.1 \mathrm{M}$ phosphate buffer containing $1 \times 10^{-4} \mathrm{~mol} / \mathrm{L}$ dopamine at different scan rate (a-j): 20, 40,60, 80, 100, 120,140,160, 180 and $200 \mathrm{mV} \mathrm{s}^{-1}$ (a); Graph of anodic peak current versus scan rate (b); Graph of anodic peak current versus the square root of the scan rate (c) 

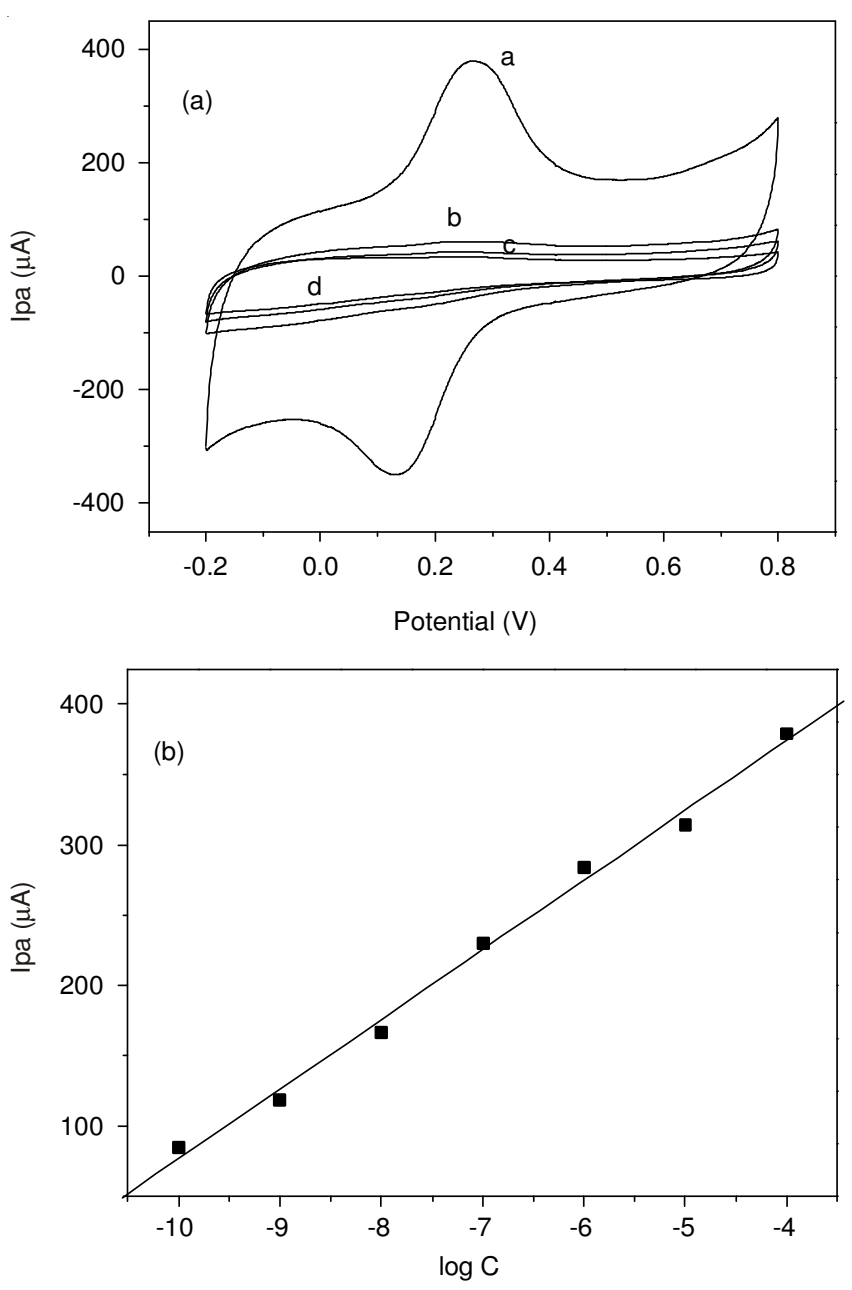

Fig. 5. Cyclic voltammograms scanned by graphene/tetraphenylborondopamine/graphite electrode in the presence of $1 \times 10^{-4} \mathrm{~mol} / \mathrm{L}$ dopamine, $0.1 \mathrm{~mol} / \mathrm{L}$ ascorbic acid and $0.1 \mathrm{~mol} / \mathrm{L}$ uric acid (a), 0.1 $\mathrm{mol} / \mathrm{L}$ ascorbic acid (b), $0.1 \mathrm{~mol} / \mathrm{L}$ uric acid (c) in $0.1 \mathrm{M}$ phosphate buffer (d) at scan rate of $100 \mathrm{mV} \mathrm{s}^{-1}$ (A); Calibrating plots of the anodic peak current versus logarithm of the dopamine concentrations in the presence of ascorbic acid and uric acid (B)

Stability and reproducibility: The stability and reproducibility of the graphene/tetraphenylboron-dopamine/graphite electrode were investigated in the PBS solution containing $1 \times$ $10^{-4} \mathrm{~mol} / \mathrm{L}$ dopamine, $0.1 \mathrm{~mol} / \mathrm{L}$ ascorbic acid and $0.1 \mathrm{~mol} / \mathrm{L}$ uric acid. For the dopamine, the relative standard deviation of the oxidation peak currents is $1.83 \%$ in 10 times successive measurements. The peak currents of the electrodes keep more than $90.2 \%$ comparing with initial values after 30 days stored in $4{ }^{\circ} \mathrm{C}$.

\section{Conclusion}

In this study, graphene/tetraphenylboron-dopamine modified graphite electrode developed for dopamine determination in the presence of ascorbic acid and uric acid shows the excellent selectivity and sensitivity at physiological $\mathrm{pH}$.
Moreover, modified electrode own the wide linear range and low detection limit. All results suggest that our investigation describe here provide a great promise for clinical diagnosis and long-term monitoring of dopamine.

\section{ACKNOWLEDGEMENTS}

The authors acknowledged the financial support form Department of Education of Liaoning Province (L2011141) and Natural Science Fund Project of Liaoning Province (20102137).

\section{REFERENCES}

1. M.L.A.V. Heien, A.S. Khan, J.L. Ariansen, J.F. Cheer, P.E.M. Phillips, K.M. Wassum and R.M. Wightman, Proc. Natl. Acad. Sci. USA, 102, 10023 (2005).

2. R.M. Wightman, L.J. May and A.C. Micheal, Anal. Chem., 60, 769A (1988).

3. I. da Cruz Vieira, Talanta, 46, 559 (1998).

4. P. Nagaraja, R.A. Vasantha and K.R. Sunitha, Talanta, 55, 1039 (2001).

5. K. Karthikeyan, G.T. Arularasu, V. Murali and K.C. Pillai, J. Pharm. Biomed. Anal., 54, 208 (2011).

6. E. Nalewajko, R.B. Ramirez and A. Kojlo, J. Pharm. Biomed. Anal., 36, 219 (2004).

7. Z.D. Peterson, D.C. Collins, C.R. Bowerbank, M.L. Lee and S.W. Graves, J. Chromatogr. B, 776, 221 (2002).

8. S.K. Yadav, P. Chandra, R.N. Goyal and Y.-B. Shim, Anal. Chim. Acta, 762, 14 (2013).

9. J.-L. Chang, G.-T. Wei and J.-M. Zen, Electrochem. Commun., 13, 174 (2011).

10. A.K. Dengler and G.S. McCarty, J. Electroanal. Chem., 693, 28 (2013).

11. L.Y. Jin, X. Gao, L.S. Wang, Q. Wu, Z.C. Chen and X.F. Lin, J. Electroanal. Chem., 692, 1 (2013).

12. A.K. Geim and K.S. Novoselov, Nat. Mater., 6, 183 (2007).

13. J.D. Fowler, M.J. Allen, V.C. Tung, Y. Yang, R.B. Kaner and B.H. Weiller, ACS Nano, 3, 301 (2009).

14. J.G. Qiu, P. Zhang, M. Ling, S. Li, P.R. Liu, H.J. Zhao and S.Q. Zhang, ACS Appl. Mater. Interfaces, 4, 3636 (2012).

15. D. Lin and R.B. Kaner, Science, 320, 1170 (2008).

16. D. Li, M.B. Müller, S. Gilje, R.B. Kaner and G.G. Wallace, Nat. Nanotechnol., 3, 101 (2008).

17. R.M. Westervelt, Science, 320, 324 (2008).

18. Y.J. Guo, L. Deng, J. Li, S.J. Guo, E.K. Wang and S.J. Dong, ACS Nano, 5, 1282 (2011).

19. Y.J. Guo, S.J. Guo, J.T. Ren, Y.M. Zhai, S.J. Dong and E.K. Wang, ACS Nano, 4, 4001 (2010).

20. J.P. Song, J. Qiao, S.M. Shuang, Y.J. Guo and C. Dong, J. Mater. Chem., 22, 602 (2011).

21. Y. Guo, Y. Chen, Q. Zhao, S. Shuang and C. Dong, Electroanalysis, 23, 2400 (2011).

22. Y.J. Guo, J. Li and S.J. Dong, Sens. Actuators B, 160, 295 (2011).

23. M. Giannetto, A. Bello, M. Gennari, L. Marchio` and G. Mori, Sens. Actuators B, 133, 235 (2008).

24. M.M. Khater, Y.M. Issa and S.H. Mohammed, Bioelectrochemistry, 77, 53 (2009).

25. V. Young, Encyclopedia of Analytical Chemistry, John Wiley \& Sons, Ltd., USA, pp. 1-31 (2006).

26. Y. Hernandez, V. Nicolosi, M. Lotya, F.M. Blighe, Z.Y. Sun, S. De, I. McGovern, B. Holland, M. Byrne, Y. Gun'ko, J. Boland, P. Niraj, G. Duesberg, S. Krishnamurthy, R. Goodhue, J. Hutchison, V. Scardaci, A.C. Ferrari and J.N. Coleman, Nat. Nanotechnol., 3, 563 (2008). 